\title{
MEDIA BARU DIGITAL SEBAGAI PERETAS KONTEKS KOMUNIKASI ANTAR PRIBADI DAN KELOMPOK
}

\author{
Reza Praditya Yudha, Irwansyah \\ Departemen Ilmu Komunikasi Fakultas Ilmu Sosial dan Ilmu Politik \\ Universitas Indonesia \\ rezapradityayudha@hotmail.com, dr.irwansyah.ma@gmail.com
}

\begin{abstract}
$D$ igital media creates a gap in the definition of the communication context created by West \& Turner (2010). Situational boundaries are increasingly unclear when in the whole process the number of participants, distance, space, feedback, media functions, and variety of channels are integrated. This study aims to analyze the implications of digital media functions in elaborating interpersonal communication to successfully mobilize groups. The study was conducted by reviewing the literature on new digital media theories. As a result, connectedness occurs as a character of interpersonal communication in digital new media. When these context is elaborated by digital media so that integrating more participants, interaction is not just merely connection anymore, but focuses on shared meaning. At this point the context is shifted into group communication.
\end{abstract}

Keywords : new digital media, communication context, interpersonal communication, group communication

\begin{abstract}
ABSTRAK
$\mathrm{M}$ edia digital membuat celah atas definisi konteks komunikasi West \& Turner (2010). Batas situasional semakin tidak jelas ketika dalam seluruh proses jumlah partisipan, jarak, ruang, umpan balik, fungsi media, dan jenis saluran saling terintegrasi. Penelitian ini bertujuan untuk menganalisa implikasi fungsi media digital dalam mengelaborasi komunikasi antar pribadi hingga berhasil memobilisasi kelompok. Kajian dilakukan dengan telaah literatur pada teori-teori media baru digital. Hasil penelitian menjelaskan, dalam media baru digital terjadi connectedness sebagai karakter komunikasi antar pribadi. Ketika konteks tersebut diretas media digital, mengintegrasikan lebih banyak partisipan, interaksi bukan sekedar koneksi, namun menitik beratkan pada shared meaning. Pada titik inilah koneksi antar pribadi dielaborasi menjadi komunikasi kelompok.
\end{abstract}

Kata kunci : media baru digital, konteks komunikasi, komunikasi antar pribadi, komunikasi kelompok 
Reza Praditya Yudha, Irwansyah

\section{PENDAHULUAN}

Karakter media baru digital menyisakan pertanyaan atas keberlakuan definisi konteks komunikasi yang dibuat West \& Turner (2010). Konteks komunikasi adalah pengategorisasian atau pengelompokan yang dibuat untuk mempermudah pemahaman atas perspektif dan proses komunikasi. Konteks komunikasi tersebut mengobservasi secara situasional berdasarkan jumlah orang, ruang, umpan balik, dan karakter saluran pesan. Konteks komunikasi mempunyai fokus penekanan berbeda untuk mengenali sebuah proses komunikasi. Berdasarkan elemen-elemen tersebut, komunikasi dibedakan dalam konteks intrapribadi, antar pribadi, kelompok, organisasi, massa/media, dan budaya.

Saat ini, batas konteks situasional semakin tidak jelas ketika komunikasi terjadi pada media digital. Dimana dalam seluruh proses, jumlah partisipan, jarak ruang, umpan balik, fungsi media, dan jumlah saluran saling terintegrasi.

Sebuah fenomena menarik tentang konteks komunikasi antar pribadi yang terelaborasi menjadi kelompok adalah pada perseteruan Ria Ricis versus masyarakat Tulungagung.

Selebgram Ria Ricis mendapat kecaman warga Tulungagung yang tersinggung dengan ujaran di instagram pribadinya. Awalnya, Ria terganggu karena fotonya diambil tanpa ijin oleh oknum Polres Tulungagung. Foto tersebut digunakan untuk banner larangan melakukan Kiki Challenge. Namun tidak ditujukan untuk oknum Polres, Ria justru menyebut "warga
Tulungagung" dalam caption. Warga yang merasa mempunyai identitas kelompok sebagai penduduk Tulungagung merasa tersinggung. Hingga akhirnya, akun media sosial Ria dipenuhi bully warga Tulungagung selama beberapa pekan (jppn.com, 9/8/2018).

Kasus lain, pada Januari lalu terjadi tawuran massal pelajar dari tiga SMK di Jakarta Barat. Tawuran ditengarai dari ejekan antar pribadi di instagram (tribunnews.com, 12/1/2018) yang kemudian menimbulkan solidaritas, hingga berbuah aksi anarkis kelompok yang menyebabkan korban mengalami luka bacok di sekujur tubuh. Dua kasus tersebut menjadi contoh komunikasi dalam konteks pribadi yang menggunakan media digital yang akhirnya menimbulkan reaksi kelompok, bahkan menimbulkan reaksi sosial.

Dari dua peristiwa tersebut, penulis tertarik untuk menganalisis bagaimana implikasi fungsi media digital dalam mengelaborasi komunikasi antar pribadi hingga berhasil memobilisasi kelompok? Penulis juga merefleksikan fenomena tersebut untuk pertanyaan, apakah perkembangan media digital membuat konteks situasional tidak lagi penting hingga mempersulit pemahaman atas komunikasi itu sendiri?

\section{PEMBAHASAN}

Media menjadi keniscayaan dalam sebuah komunikasi. Histori evolusi media menjadi satu runutan bagaimana praktek komunikasi menjadi sebuah disiplin ilmu. Media sebagai sarana transmisi pesan menjadi wujud dan fungsi sehingga komunikasi dapat 
diamati. Di awal kemunculannya, fungsi media massa berkembang pesat di Amerika sebagai alat untuk menyamakan persepsi bersama. Evolusi media untuk komunikasi ditelusuri Schramm (1988) dengan menceritakan kronologinya sebagai sarana penyampai pesan mulai jejak lukisan tangan di gua, hingga saat ini, dalam bentuk digital.

Rogers (1997) juga mengkaji perkembangan media. Mulai dengan mendokumentasikan pesan lukisan gua di Spanyol, kalender perbintangan, bentuk verbal (bahasa dan tulisan), dan non verbal. Rogers kemudian melanjutkan histori media pada perkembangan era Neolitik hingga Homo Sapiens. Dimana saat itu, media massa dan institusi komunikasi banyak bermunculan. Misalnya dalam bentuk kantor berita, perusahaan iklan, agen public relations, Press Amerika.

Media akhirnya berubah akibat pengaruh perkembangan teknologi. Media tidak hanya dalam bentuk koran cetak, namun juga dapat ditemui dalam wujud audio seperti musik atau radio. Juga bentuk visual media yang berkembang seperti foto, video, film, atau televisi. Produk-prduk budaya populer tersebut sangat signifikan memengaruhi perubahan kecepatan kehidupan manusia. Terakhir, Schramm menjelaskan era komputasi dan membuat gambaran masa depan komunikasi. Contohnya saat ini, media digital mampu mengintegrasikan semua hal tersebut dalam satu media. Singkatnya, Schramm mendeskripsikan komunikasi sebagai kemampuan manusia melewati dan mengatasi batas, melalui era tulisan hingga digital.

\section{Memahami Media Digital Baru}

Media baru digital membedakan konsep mediasi dan mediatization. Miskonsepsi dalam pemahaman kedua terma tersebut, membawa dampak secara metodogi dan konseptualisasi teori.

Dalam mediatisasi, institusi sosial atau institusi fisik sangat berpengaruh. Proses mediatisasi adalah relasi dua arah dimana institusi mengikuti aturan atau cara kerja media (media logic). Karakter mediatisasi adalah memperluas, menggantikan, dan menggabungkan proses interaksi manusia. Karenanya, mediatisasi membuat masyarakat semakin terikat, tergantung pada media, dan mematuhi media logic (Couldry, 2008). Media sendiri menjadi sistem independen yang mempengaruhi praktek sosial.

Sedangkan pembahasan media baru digital adalah diskusi tentang fungsi mediasi. Apa yang diproses oleh media baru digital yang meliputi seluruh input koding data dalam bentuk bilangan biner 0 1. Media baru dalam bentuk digital hanya menjadi sarana pesan koding yang diinput, untuk disampaikan pada avatar lain tanpa mengenali sifat analog user (kemarahan, kegembiraan, prasangka, pelupa, atau ketidakpastian).

Nansen dan Jayemanne (2016) menemukan hasil riset bahwa pengguna paling tinggi adalah remaja. Namun dengan keterangan lanjutan yang sangat penting bahwa keberadaan media digital seolah menjadi hal natural saat ini bagi siapapun. Atau dengan kata lain, segala usia, status ekonomi, wilayah, dan lapisan masyarakat sudah bisa menerima keberadaannya. Bahkan mereka mampu 
Reza Praditya Yudha, Irwansyah

mengoperasikan secara otodidak. Misalnya diawali dengan pola asuh orang tua pada anak yang tidak membatasi interaksi dengan media.

Tabel I

Dimensi Komunikasi antar pribadi dalam media baru digital

\begin{tabular}{||c|c|c|}
\hline ELABORASI & KONTEKS & EFEK \\
Percakapan berkelanjutan & Koneksi perpetual & Mediasi \\
Memperkuat kedekatan & Kehadiran yang terhubung & Intemediasi \\
Polimedia & & Remediasi \\
Mode pervasif & & \\
\hline
\end{tabular}

Sejak era konvensional media seperti TV, kemudian praktis sebagaimana telfon genggam, hingga teknologi layar sentuh yang sangat mudah saat ini; intermediation terjadi tanpa banyak disadari. Melalui hal sederhana seperti saat memerlihatkan video lagu anak di YouTube, berkomunikasi melalui panggilan video, atau mengajak diskusi secara virtual.

Pengasuhan orang tua dengan pengaruh media digital, juga menjadi perantara anak dalam memahami konsep ruang domestik dan jaringan publik. Bahkan Forbes membuat riset yang menemukan bagaimana Generasi $\mathrm{Z}$ memahami dunia dengan bantuan gawai.

\section{Era Gen-Z}

Media baru digital melahirkan era Generasi Z (Gen-Z). Era generasi yang disebut anti-milenial. Mereka mempunyai mekanisme pengenalan selayaknya "detektor", ketahanan, dan adaptasi lebih terhadap perkembangan teknologi dan media yang mempengaruhi budaya. Sedangkan generasi sebelumnya, milenial, cenderung hanya menjadi pengguna yang memahami realitas berdasarkan media.

Analogi perbedaan generasi milenial dan gen-z bisa dicontohkan seperti ketika mereka menikmati video di Youtube atau iklan di platform aplikasi, instagram. Generasi milenial begitu terkesima dengan beauty vlogger, selebgram, atau influencer. Gnerasi era milenial dengan mudah percaya, meniru, dan berkiblat pada model, karena melihat sang Selebgram terlihat cantik atau tampan. Mereka berfikir akan bisa sama rupawan dengan sang Model ketika mengenakan barang yang sama.

Generasi Z lebih memahami, bahwa apa yang cocok untuk seorang influencer atau vlogger, belum tentu tepat untuk mereka. Gen-Z memahami peran dan fungsi vlogger atau influencer tersebut. Media baru digital bukan hanya melahirkan, namun juga melipatgandakan eksistensi Gen-Z.

Gen-Z mewakili $1 / 3$ populasi dunia atau sekitar 7.7 miliar penduduk bumi yang lahir sejak tahun 2001 (Forbes, Oktober 2018). Mereka adalah generasi moderen, anti-millenial, tech-savvy millenial, self-made youtube stars, wirausahawan kreatif dari bisnis on-line, pengode ahli, dan memahami dunia hanya dari gawai.

Gen-Z lahir di tengah fenomena sosial tentang resesi besar ekonomi, pernikahan sesama jenis, penggunaan mariyuana, terorisme, pemanasan global, dan kekerasan senjata. Karakter gen-z adalah sebagai berikut :

1. Norma gender baru : Generasi $\mathrm{Z}$ tidak lagi mendefinisikan personal seseorang berdasarkan gender. Tiap 
orang adalah unik dan berbeda, tidak perduli dengan gender yang dimiliki. Bahkan konstruksi sosial atas ras, agama, atau kesukuan jua tidak dijadikan sebagai identitas generasi Z. Mereka lebih berorientasi pada pribadi masingmasing individu.

2. Lebih socially-minded : Generasi Z menggunakan media digital untuk membangun relasi sosial. Terlepas apakah bentuk kelompoknya dalam media digital atau nyata, mereka tetap berusaha diterima oleh kelompok. Pada proses adaptasi dan pencarian kelompok, Generasi Z menyadari efek sebuah material, seperti merek, produk, atau objek, agar diterima kelompok sosialnya.

3. B.S Meter kuat : Generasi Z mempunyai sebuah sensibilitas untuk memahami berita palsu, kemampuan menganalisa kepentingan dibalik wacana, mementingkan otentitas, originalitas, dan mempunyai filter kuat atas wacana bohong.

4. In-store shopping : Generasi Z meskipun memahami cara interaksi da operasional sebuah marketplace daring, masih menyukai belanja langsung. Generasi $\mathrm{Z}$ mengenali kelebihan dan kekurangan berbelanja melalui daring. Misalnya, meskipun lebih murah, Generasi Z memahami resiko potensi penipuan, kebohongan, atau masalah teknis akibat kecerobohan membaca informasi.

5. Embrace individuality : Generasi $\mathrm{Z}$ lebih mementingkan keunikan individu, berani menonjolkan kepribadian, cenderung menyukai eksklusivitas, hubungan timbalbalik, interaktif, dan bertanggung jawab.

6. Frugal \& Debt avers : Generasi Z mementingkan harga dan kualitas. Mereka memperhitungkan cost yang dikorbankan untuk mendapatkan sesuatu, tidak suka berhutang, ekonomis, dan lebih menyukai kesepakatan sebelum membeli.

\section{Tren Komunikasi Antar Pribadi dalam Media Digital}

Media baru digital membuat hampir semua proses komunikasi bisa terjadi secara langsung. Schroeder (2017) bahkan mengamati perubahan ini bukan hanya pada proses komunikasi antar pribadi, namun hingga komunikasi massa. Misalnya, bagaimana komentar umpan balik langsung bisa ditayangkan dari akun twitter untuk menjawab pertanyaan pemandu televisi.

Meskipun saat ini terkonvergensi, perkembangan media digital sebenarnya tidak menghilangkan esensi pentingnya hubungan dalam komunikasi antar pribadi (Madianou \& Miller, 2012). Konvergensi diistilahkan Madianou dan Miller sebagai polymedia, dimana sebuah teknologi tidak hanya berfungsi tunggal. Namun polimedia memungkinkan berbagai platform dijalankan hanya melalui satu gawai.

Komunikasi antar pribadi dari konteks pembicaraan biasanya menuju ke keintiman atau keakraban. Karena itu, beberapa riset tertarik melihat persahabatan, romantisme, atau hubungan keluarga. Hal ini sebagaimana juga ditemukan dalam observasi Coyne 
Reza Praditya Yudha, Irwansyah

et.al (2013) pada pengguna media digital remaja. Selain berselancar internet dan mendengarkan musik, media digital memberikan kepuasan otonomi, menciptakan identitas sosial, dan kebutuhan intimasi sebagaimana mereka inginkan.

Avatar dalam media baru digital mempunyai identitas yang dibuat oleh user, yang bisa saja asli atau dibuat-buat. Identitas, asal, status sosial, dan budaya pada komunikasi antar pribadi dalam media digital terkadang ditunjukkan, atau justru disembunyikan. Hal ini bergantung pada intensi dan orientasi masing-masing pengguna. Misalnya ketika membuat akun, seseorang menggunakan nama marga karena mempunyai intensi menemukan rekan satu daerah di perantauan. Sementara di lain pihak, justru ada yang menggunakan nama samaran ala Korea karena ingin terafiliasi dengan kelompok penggemar artis Korea. Mazhari (2015) menunjukkan temuan riset, bahwa kesamaan identitas profil akun media sosial menjadi alat pengenal yang banyak direkomendasikan ketika seseorang memperluas jaringan persahabatan.

\section{Media Digital Mengelaborasi Komunikasi Kelompok}

Penggunaan media digital yang awalnya untuk membentuk afiliasi seorang individu juga menciptakan berbagai fungsi sosial. Sebuah profil avatar bisa dilengkapi dengan informasi, preferensi, dan dilihat jejak digitalnya. Hal-hal tersebut memudahkan untuk membentuk kelompok yang dibuat berdasarkan kesamaan sosial. Yang menarik, selain untuk memperluas sebaran jaringan, media digital digunakan juga untuk membentuk identitas bahkan menciptakan legitimasi kelompok. Dengan mengunggah aktivitas bersama, diskusi umum, atau siaran langsung; seolah eksistensi kelompok telah dijustifikasi. Masyarakat luas akan tertarik sehingga kuantitas dan kelestarian kelompok akan langgeng.

Beberapa fungsi lebih spesifik media digital untuk kelompok timbul akibat kebutuhan arus interaksi terkait pekerjaan profesional. Bahkan akhirnya, kapasitas media digital yang tidak terbatas membuat komunikasi berkembang menjadi konsumsi publik. Misalnya interaksi antara pemimpin daerah dengan masyarakat lokal atau jurnalis dengan masyarakat setempat (Kim, dkk, 2016). Gubernur Jawa Barat Ridwan Kamil banyak mengatasi permasalahan pemerintahan melalui akun instagram @ ridwankamil. Masyarakat bebas mengadu, mencari informasi, hingga berkelakar hal pribadi. Bahkan RK ketika rapat pimpinan perdana menyerukan semua dinas pemerintah daerah untuk mempunyai dan aktif berinteraksi melalui media sosial (pikiran-rakyat.com, 18/9/2018.

\section{Konektivitas dan Interaksi dalam Antar Pribadi pada Media Baru}

Media digital antar pribadi bukan berarti tidak terjadi dalam konteks sosial. Media baru digital tetap menjadi sarana pertukaran pengetahuan terkait dengan peran sosial. Fungsi komunikasi antar pribadi untuk menciptakan keakraban atau keintiman, tetap bisa terjadi dalam ruang digital. Bahkan media baru digital 
menciptakan indikator baru kedekatan pribadi melalui relasi tinggi-rendahnya interaksi. Pada komunikasi dalam sebuah relasi famili, contohnya. Keintiman dan kedekatan anggotanya bisa diukur frekuensi, durasi, atau intensi interaksinya dalam ruang digital.

Jika pada ruang analog, komunikasi antar pribadi dinilai berdasarkan konteks kedekatan relasinya. Maka pada media baru digital, konteks tersebut dinilai berdasarkan derajat tinggi atau rendahnya interaksi hubungan.

Disinilah letak perspektif mediasi mulai penting untuk ditekankan. Bahwa media digital hanya menilai berdasarkan data kuantitatif atas inormasi yang telah diinput. Ia menggunakan bilangan algoritma untuk membuat definisi atas sesuatu. Karenanya, ia akan terjadi hanya ketika avatar user terkoneksi, secara terus-menerus.

Media baru digital juga mengekstensi perbincangan hingga tidak hanya pada sebuah ruang dan waktu, namun juga berbagai konteks. Contohnya komunikasi antara dosenmahasiswa, dokter-pasien, atau atasankaryawan; bukan hanya di kelas atau rumah sakit. Aktivitas peran dalam polimedia bisa berlanjut melalui grup whatsapp atau email. Komunikasi avatar dokter dan pasien bisa terjadi bahkan ketika user telah berada di rumah atau sebuah kafe. Robert, dkk. (2017) mengistilahkannya sebagai interactivity, dimana interaksi bukan hanya melibatkan aspek sosial, namun juga aktivitas tekstual dan teknis.

Karakter polimedia membuat media baru digital ini berbeda dalam beberapa kemampuan. Ia menjadi teknologi yang bisa menjadikan sebuah alat mengoperasionalkan berbagai platform internet dan platform aplikasi gawai. Namun demikian, media baru digital mempunyai keterbatasan storage. Pesan komunikasi antar avatar tidak akan terhapus atau hilang selama media penyimpanan mempunyai kapasitas cukup.

\section{Gambar I. Komunikasi antar Pribadi dalam Media Baru Digital}

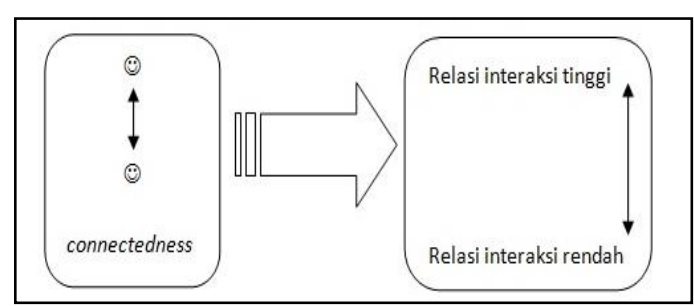

Perbedaan media baru digital adalah juga pada replikabilitas. Media baru dalam bentuk digital bisa membuat user menghapus, memanipulasi, bahkan menunda respon pesan. Karena itu, struktur temporal media baru bisa diatur apakah berjalan secara berurutan atau tidak. Misalnya ketika pesan si A dikirim Senin dan si B dikirim Rabu setelahnya untuk si C. Avatar si C menerima pesan keduanya seketika setelah masingmasing mengirim. Meskipun avatar si $\mathrm{C}$ menerima pesan avatar A lebih cepat, namun user $\mathrm{C}$ lebih memilih untuk membalas pesan si B lebih dahulu. Karenanya, komunikasi antara avatar si A dan $\mathrm{C}$ akan ditunda oleh user $\mathrm{C}$ meskipun telah diterima lebih cepat.

Komunikasi antar pribadi melalui avatar dalam media baru digital sarat dengan berbagai isyarat sosial (social cues). Ia bukan hanya berupa pesan visual dan auditori, namun juga

\section{Islamic Comunication Journal


Reza Praditya Yudha, Irwansyah

kontekstual. Misalnya bagaimana ketika proses pertukaran pengetahuan tetap memasukkan unsur norma dan nilai sekalipun melalui media sosial. Nilai dan norma inilah yang menjadi kuantum yang membentuk pola peran dan mengatur proses komunikasi antar avatar.

Ketika avatar seorang mahasiswa berinteraksi dengan avatar dosen, akan menggunakan lambang atau tanda digital yang menyiratkan penghormatan. Sekalipun, dalam dunia digital, hal tersebut sebenarnya tidak memberi dampak apapun pada avatar. Pada dimensi digital, semua avatar mempunyai kedudukan sama, equal. Manusia lah yang memasukkan input social cues tersebut sehingga termanifestasi dalam ekosistem interaksi digital.

Polimedia dan bentuk berbeda media baru bukan hanya menjadi mediasi, namun juga memungkinkan intermediasi atau remediasi. Intermediasi misalnya penggabungan beberapa bentuk pesan dalam satu media. Misalnya penggabungan beberapa foto, teks, dan lagu menjadi video untuk diungah di YouTube. Atau remediasi, dengan membuat medium baru dari sebuah media lain. Misalnya, sebuah ide diinput menjadi teks dalam posting facebook, kemudian didokumentasikan untuk menjadi sebuah e-book.

\section{Sharing Memory Kelompok di Media Baru Digital}

Komunikasi kelompok di media baru digital ditandai dengan terciptanya sebuah memori bersama (collective memory). Informasinya tentu diterima tiap-tiap avatar yang dioperasionalisasi oleh manusia pada dunia nyata. Misalnya pada kasus Ria Ricis, avatar Ria Ricis menransmisi pesan pada seluruh avatar publik yang mempunyai lingkaran konsentris pada satu informasi, Kabupaten Tulungagung. Beberapa avatar tersebut bahkan membuat kelompok virtual.

\section{Gambar II Komunitas Virtual dalam}

\section{Platform Aplikasi Instagram}

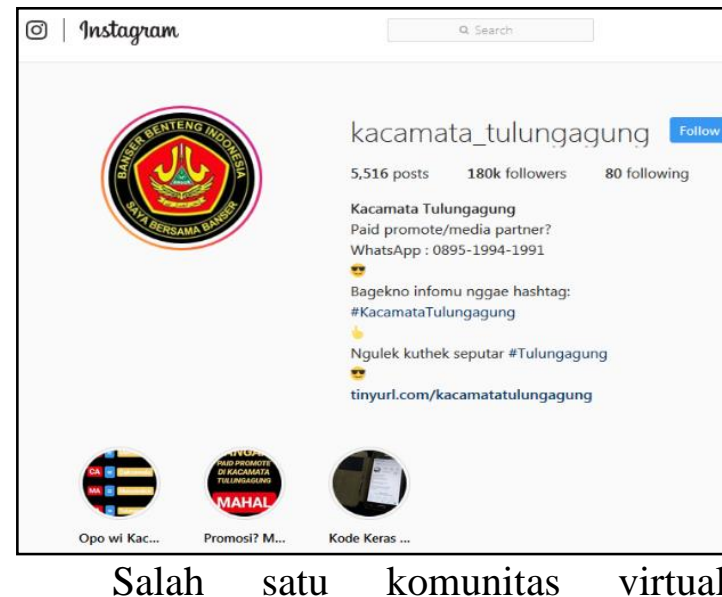

tersebut Kacamata Tulungagung, misalnya, sebagai komunitas virtual bisa dikatakan mempunyai collective intelligence berupa pengalaman bersama atas Kabupaten Tulungagung. Users dari avatar tersebut berasal, mempunyai pengetahuan, atau ketertarikan atas Kabupaten Tulungagung. Adanya kesamaan memori yang dilekatkan beberapa users pada avatarnya masingmasing, menciptakan kebersamaan.

Kelompok virtual menciptakan sebuah lingkungan nyata (real interface of memory) dalam media baru digital. Memori kelompok menjadi motif yang menyenangkan users untuk tetap berinteraksi bersama dengan komunitas virtual. Mereka merasakan kepuasan 
relasi yang diorganisasi dan dibentuk bersama.

Ketika avatar Ricis menransmisi pesan untuk memori kolektif kelompok, akan menimbulkan respon komunitas virtual tersebut. Respon tersebut bisa saja menjadi internauts, dibawa users hingga dunia nyata, atau extropian yang hanya meninggalkan memori dalam ekosistem internet. Karenanya, bisa saja users yang mempunyai karakter internauts membuat sebuah laporan polisi. Atau sebaliknya, user extropian yang tetap mempunyai hubungan baik dalam dunia nyata meskipun di facebook bersilang pendapat. Perilaku internauts inilah yang juga nampak pada pelaku tawuran. Mereka sebagai users terjebak pada memori lingkungan virtual. Kelompok user menganggap dunia nyata saling berkaitan dengan ekosistem yang diciptakan dalam dunia virtual (ecodependent).

Kebersamaan yang menciptakan memori kolektif sebenarnya juga bisa dimanfaatkan. European Commission-i3 sejak tahun 1997 sampai 2000, memanfaatkan adanya hubungan antara media digital dengan memori, komunitas, dan ruang kota dalam Proyek LiMe (Casalegno, 2004). Proyek tersebut menempatkan media-media digital di tempat-tempat umum yang bisa digunakan untuk mencari, berbagi, dan mengeksplorasi memori dan pengalaman kolektif. Selain menemukan informasi lokal menarik, masyarakat juga bisa mengekspresikan ide melalui media digital tersebut.

Proyek LiMe mendukung penciptaan dan distribusi konten informal, serta meningkatkan mobilisasi masyarakat lokal. Diharapkan, dari proyek ini, interaksi sosial yang selama ini dirasakan berkurang akibat perkembangan teknologi, justru dengan munculnya media digital bisa ditingkatkan. Dengan kata lain, perkembangan media ini dianalogikan sebagai pisau. Ia memang bisa mengiris jai tanpa sengaja. Namun proyek LiMe justru menggunakan pisau tersebut untuk memotong perban, demi melindungi luka dari infeksi.

Gambar III Kompetensi Komunikasi dalam Media Digital

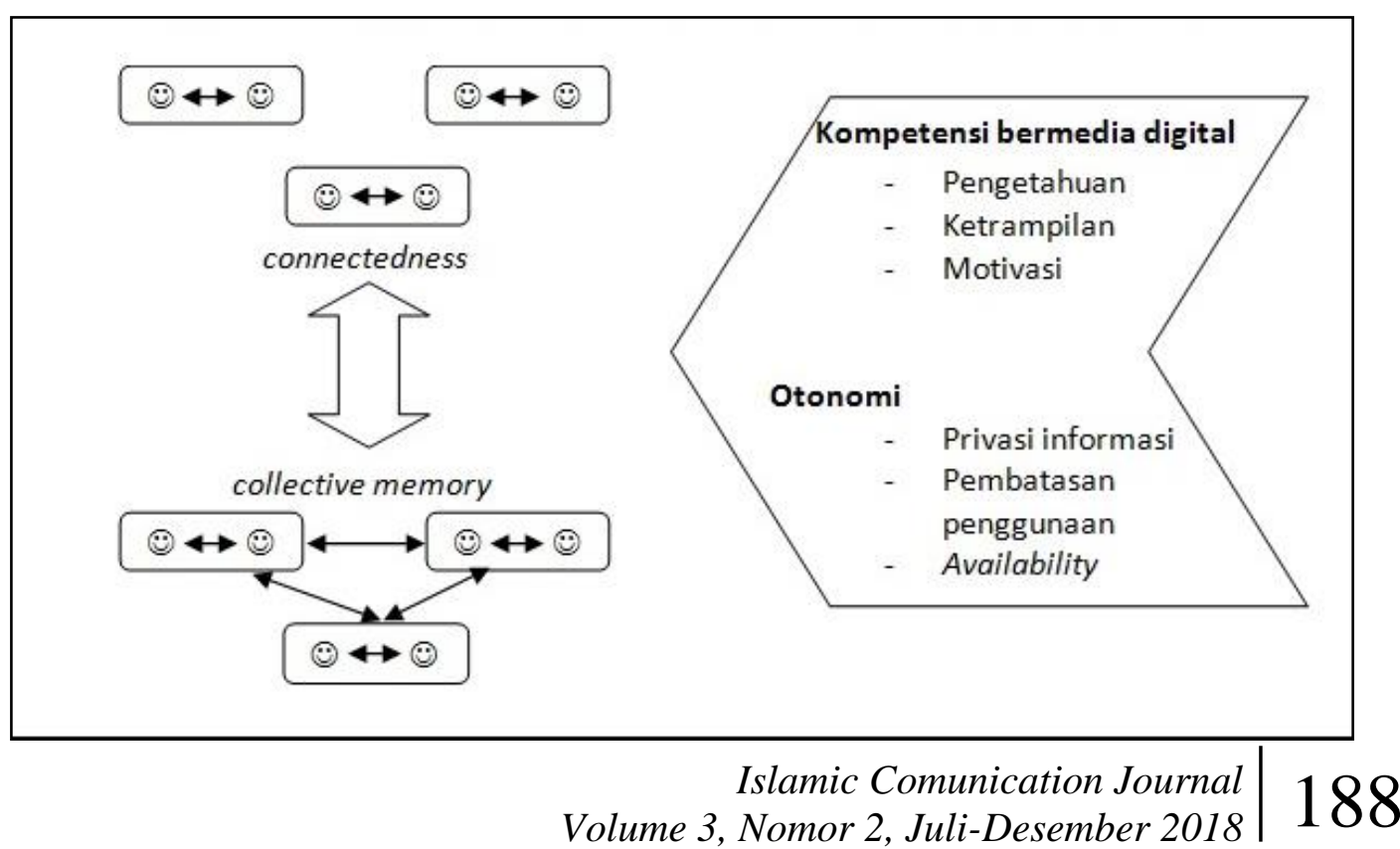


Reza Praditya Yudha, Irwansyah

Kompetensi komunikasi menyaratkan adanya pengetahuan, motivasi, dan ketrampilan (Guddykunts \& Kim, 1997). Sama halnya dalam media baru digital, pengetahuan individu yang menjalankan akun digital didapatkan melalui literasi. Ketrampilan mengoperasionalkan aplikasi internet atau aplikasi media digital, dimungkinkan dengan adanya akses. Dan motivasi individu yang mengontrol avatar, diperkuat ketika mempunyai keterjangkauan.

Gawai memberi otonomi individu, namun kompetensi bermedia membuat batasan atas hak tersebut. Setiap orang bisa mengoperasikan media digital, membuat avatar, atau berkomentar dengan bebas. Namun kompetensi bermedia menentukan apakah orang tersebut termasuk dalam kategori smat user, wise user, atau bukan keduanya.

Smart user secara teknis mengerti cara penggunaan gawai, membuat avatar, ragam platform internet atau aplikasi, dan bisa menjalankan. Wise user bukan hanya memahami operasional bermedia digital, namun memahami konsekuensinya. Ia akan berfikir sebelum menyebarkan pesan, mencari banyak sumber referensi, mengenali berita bohong atau terverifikasi. Users yang tidak begitu memahami penggunaan gawai atau media baru, sekaligus tidak mampu memahami dampak komunikasi digital; akan cenderung kesulitan dan tetap menggunakan cara konvensional.

User karenanya harus memahami efek media baru. Privasi, misalnya, akan selalu dapat ditelusuri berdasarkan informasi, identitas, dan jejak digital avatar. Pertukaran informasi, frekuensi percakapan, dan waktu user yang dihabiskan dalam mengaktifkan avatar juga memerlukan pembatasan.

Sekalipun komunikasi antar pribadi dan kelompok melalui media digital mempunyai dimensi keintiman dan keakraban, kompetensi komunikasi tetap menjadi bahasan penting. Hal ini karena tujuan utama dari komunikasi, apapun level dan konteksnya, adalah penyampaian pesan secara efektif. Justru karena melalui media, potensi gangguan teknis dan semantik akan semakin besar (Hwang, 2011).

Ketika berkomunikasi langsung, informasi akan diterima secara komprehensif. Artinya, antara bahasa nonverbal dan verbal akan menjadi komplementer yang saling melengkapi. Sehingga dalam menginterpretasi, redundansi pesan semakin tinggi dan ketidakpastian semakin rendah. Lebih utama, kompetensi komunikasi antar pribadi atau kelompok melalui media digital tetap dibutuhkan agar makna pesan dapat diterima sebagaimana diinginkan.

Ketiga elemen kompetensi; pertama, motivasi partisipan untuk bersedia saling membuka diri, membagi informasi, dan mendengarkan yang lain. Hal ini agar masing-masing pihak mempunyai kedudukan yang sama sehingga kesamaan antar pribadi semakin besar. Dalam dunia digital, posisi antar avatar satu ke avatar lain adalah equal. Manusia yang mengoperasikan avatar tersebutlah yang membuat sosial cues hingga menjadikan sebuah pembagian kerja atau struktur antar avatar. 
Media Baru Digital Sebagai Peretas... hal.180-192

Kedua, partisipan tetap harus mempunyai pengetahuan tentang siapa yang terlibat dalam komunikasi. Misalnya pengetahuan tentang latar belakang budaya, pendidikan, atau ekonomi lawan bicara. Dengan pengetahuan ini, seseorang bisa memroduksi pesan sesuai kemampuan penerima. Ketiga, ketrampilan agar pesan sukses dikirim melalui media yang tepat, efisien, dan efektif. Pada elemen ketiga dari kompetensi komunikasi inilah perkembangan media digital sangat menonjol. Misalnya apakah seseorang mampu mengoperasikan sebuah aplikasi, mampu mengemas pesan, dan memahami perangkat yang diperlukan agar pesan sampai tepat waktu.

\section{PENUTUP}

Semua konteks komunikasi saat ini bisa dimediasi hingga mendapatkan umpan balik langsung, jarak, waktu, dan kapasitas partisipan tidak terbatas. Media digital membuat informasi dan orientasi pembicaraan tidak hanya pada satu konteks komunikasi. Hal pribadi dalam media sosial bisa menjadi konsumsi kelompok, bahkan menyita komunikasi massa. Situasi komunikasi juga tidak terbatas karena media digital menjadi perantara pertukaran informasi, alat artikulasi pengalaman, dukungan teknis, hingga pemicu simpati yang menciptakan sebuah persahabatan atau kelompok. Dengan kata lain, connectedness yang menjadi karakter komunikasi antar pribadi di media baru digital dapat berkembang dengan integrasi partisipan sehingga memungkinkan terjadinya shared
meaning.

Keberadaan semua konteks komunikasi tetap menjadi keniscayaan dalam interaksi, sekalipun dalam media baru digital. Users tidak hanya berada dalam koneksi dan relasi interaksi dua avatar. Dua atau lebih avatar bisa membuat, berbagi, dan merespon memori bersama. Sementara, user juga bisa berlaku internaut atau ekstropian sesuai kompetensinya yang membatasi informasi hanya pada avatar atau dimanifestasikan dalam dunia nyata. Pada akhirnya, fenomena dan media telah berkembang. Namun esensi komunikasi sebagai usaha menransmisi dan menginterpretasi pesan secara efektif, efisien, dan kompeten, sampai saat ini belum berubah.

\section{Daftar Rujukan}

Gudykunst, William B. dan Young Yun Kim. (1997). Communicating with Strangers : An Approach to Intercultural Communication. New York : McGraw-Hill.

Rogers, E.M.(1997). A History of Communication Study : A Biographycal Approach. New York : Free Press.

Schramm, Wilber Lang. (1988). Story of Human Communication : Cave Painting to Microchip. US : Harper \& Row. 


\section{Jurnal :}

Casalegno, Federico. (2004, SAGE). "Thought on the Convergence of Digital Media, Memory, and Social and Urban Spaces", Space \& Culture Vol. 7 No. 3.

Couldry, Nick. (2008). "Mediatization or Mediation?

Alternative

Understanding of the Emergent Space of Digital Storytelling".

The London School of Economics and Political Science : New Media and Society 10(3) p. 373-391.

Coyne, Sarah M., Laura M PadillaWalker, \& Emily Howard. (2013, SAGE) "Emerging in a Digital World : A Decade Review of Media Use, Effect, and Gratifications in Emerging Adulthood". Emerging Adulthood I (2) p. 125-137.

Cui, Di. (2016, SAGE) "Beyond Connected Presence : Multimedia Mobile Instant Messaging in Close Relationship Management". Mobile Media \& Communication Vol 4(I) p. 1936.

Hwang, Yoosun. (2011, ELSEVIER). "Is Communication Competence still Good for Interpersonal Media? Mobile Phone and Instant Messenger. Computer in Human Behaviour 27 p. 924-934.

Kim, Yonghwan., Youngju Kim, \& Na Yeon Lee. (2016, Routledge).
Reza Praditya Yudha, Irwansyah "Uses and Gratifications, Journalists' Twitter Use, and Relational Satisfaction with the Public". Routledge Journal of Broadcasting \& Electronic Media 60(3) p. 503-526.

Madianou, Mirca \& Miller, Daniel. (2012, SAGE). "Polymedia : Towards a New Theory of Digital Media in Interpersonal Communication". International Journal of Cultural Studies, 16(2) p. 169-187.

Mazhari, Sara, Seyed Mostafa Fakhrahmad \& Hoda Sadeghbeygi. (2015, SAGE). "A User-Profile-Based Friendshi Recommendation Solution in Social Network. Journal of Information Science. 2015. Vol 41(3) p. 284-295

Murray, Simone \& Weber, Millicent. (2017, SAGE). "Live and Local : The Significance of Digital Media for Writer's Festival". Convergence : The International Journal of Research into New Media Technologies Vol 23(I) p. 6178.

Nansen, Bjorn \& Jayemanne, Darshana. (2016, Routledge). "Infant, Interface, and Intermediation : Digital Parenting and the Production of iPad Baby Videos on YouTube. Routledge Journal of Broadcasting and Electronic Media 60 (4) p. 587-603.

Robert M Davidson, Carol X.J. Ou, Maris G Martisons. (2017, 
Media Baru Digital Sebagai Peretas... hal.180-192

ELSEVIER). "Interpersonal

Knowledge Exchange in China

: The Impact of Guanxi and Social Media". Information \& Management.

Schroeder, Ralph. (2017). "Towards A Theory of Digital Media". Information, Communication, and Society, (https://dx.doi.org /10.1080/1369118X.2017.1289 231).

\section{Koran On-line}

Forbes.com. Petro, Greg. "Gen Z : New Gender Norms, Fake News, Frugality, \& the Rise of Retail's Next Power Generation". https://www.forbes.com/sites/gr egpetro/2018/10/14/gen-z-newgender-norms-fake-news-

frugality-and-the-rise-of-retailsnext-power-generation/\#795661 057382 (14 Oktober 2018).

jppn.com. Ria Ricis Geram Fotonya Dipakai Tanpa Izin untuk
Spanduk.https://www.jpnn.com/ news/ria-ricis-geram-fotonya dipakai-tanpa-izin-untukspanduk (9 Agustus 2018)

pikiran-rakyat.com. Ridwan Kamil Perintahkan Semua Dinas Memiliki Akun Media Sosial. http://www.pikiran-rakyat.com/ bandung-raya/2018/09/18/ ridwan-kamil-perintahkansemua-dinas-miliki-akunmedia-sosial-430288

September 2018).

tribunnews.com. Ramadhan, Panji Baskhara. "Dipicu Saling Ejek di Media Sosial, Siswa 3 Sekolah di Jakarta Barat Terlibat Tawuran Massal". http://www. tribunnews .com/metropolitan/2018/01/12/d ipicu-saling-ejek-di-mediasosial-siswa-3-sekolah-dijakarta-barat-terlibat-tawuranmassal (12 Januari 2018). 